\title{
The different clinical significance of EGFR mutations in exon 19 and 21 in non-small cell lung cancer patients of China
}

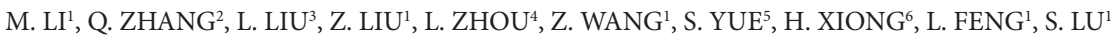 \\ ${ }^{1}$ Laboratory Center, The Second Affiliated Hospital of Dalian Medical University, Dalian 116027, Liaoning Province, P. R. China, e-mail: \\ lvshen1956@yahoo.com.cn; ${ }^{2}$ Department of Pathology, The First Affiliated Hospital of Dalian Medical University, P. R. China; ${ }^{3}$ Department of \\ Gastroenterology, The First Affiliated Hospital of Dalian Medical University, , P. R. China; ${ }^{4}$ Department of Pathology, University of Utah School \\ of Medicine, Salt Lake City, Utah 84132, USA; ${ }^{5}$ Department of Thoracic Surgery, The Second Affiliated Hospital of Dalian Medical University, \\ P. R. China; ${ }^{6}$ Department of Thoracic Surgery, The First Affiliated Hospital of Dalian Medical University, Dalian 116027, Liaoning Province, \\ P. R. China
}

Received Jun 27, 2010

\begin{abstract}
Mutations of epithelial growth factor receptor (EGFR) in exon 19 and 21 are both believed to be associated with carcinogenesis, sensitivity to tyrosine kinase drugs and with the prognosis of non-small cell lung cancers (NSCLCs). However, their exact clinical significance remains disputable. We detected the mutations of 157 NSCLCs from mainland China with high resolution melting analysis and identified exon mutations with DNA sequencing. Of the 157 cases examined, 57 displayed EGFR mutations which included 22 in exon 19 and 35 in exon 21. Current research has shown that EGFR mutations are more commonly associated with the female population and East Asians, with additional significance being adenocarcinomas. Our current findings are supporting this sugestion. We analysed the clinicalpathological characteristics of mutations in exon 19 and 21 separately, which showed that the mutation frequency of NSCLCs in exon 21, but not in exon 19, were significantly higher in females. Comparatively, mutation frequencies in exon 19 were significantly higher in the stage I and II than in the stage III abnd IV, while tumors with lymph node metastasis and the stage III and IV demonstrated significantly higher mutation frequencies in exon 21. Additionally, exon mutations in the left and right lung showed significant differences: with exon 19 mutations being more frequent in the tumors of left lung, and exon 21 mutuations showing a higher incidence in right lung tumors. This suggests that, in mainland China, NSCLCs with EGFR mutations in exon 19 could have a less malignant character than those with mutations in exon 21. It's the first report that EGFR mutations in exon 19 and exon 21 in NSCLC patients may relate to the tumor sites, but further research is still required.
\end{abstract}

Key words: EGFR; mutation; non-small cell lung cancer

Lung cancer is the leading cause of cancer-related death around the world, including China. Non-small cell lung cancer (NSCLC) comprises about $80 \%$ of all lung cancers. The occurrence and development of NSCLC involves several gene alterations by stepwise progression [1]. Epithelial growth factor receptor (EGFR) is a tyrosine kinase receptor that plays a key role in signal transduction that regulates cell proliferation, survival and differentiation during physiological development phases. Mutated EGFR activated by autophosphorylation can continuously stimulate the downstream signal pathways, promoting cellular proliferation and inhibiting apoptosis, finally leading cells to malignant transformation [1-4]. Mutations of EGFR are mainly harboured in exon 18-21 which encode the tyrosine kinase domain. Deletion mutation in exon 19 and point mutation in exon 21 are the two most common activating mutations [5]. KRAS, encoding a small GTPase downstream of EGFR, is one of proved oncogenes. KRAS activating mutation is another agent in the carcinogenesis of NSCLC $[6,7]$. The function of abnormal activation in EGFR/KRAS signal transduction in carcinogenesis, including NSCLC, was recognised many years ago. With the coming of molecular target therapy in tumors, the EGFR/KRAS signal transduction pathway was emphasised specially.

EGFR tyrosine kinase inhibitors (TKIs), such as gefitinib and erlotinib, play a role in the treatment of NSCLC through binding to EGFR tyrosine kinase domain and then inhibiting EGFR/KRAS signal transduction. Since Lynch et al and Pacz et al reported that EGFR mutations, especially in the tyrosine 
kinase domain, might predict the sensitivity to gefitinib treatment to NSCLCs in 2004, more and more research groups proved that EGFR mutations in exon 19 and 21 are the critical markers of NSCLCs sensitive to TKI drugs $[8,9]$. And then KRAS mutation, normally in codon 12 and 13 , is thought to be a biomarker to resistance to TKIs. EGFR mutation is usually exclusive to KRAS mutation. And it was thought that NSCLCs with EGFR and KRAS mutations commonly present different clinicopathological characteristics $[10,11]$. Interestingly, EGFR mutations in exon 19 and 21 are usually exclusive too [12]. However, it is still unclear if the two type mutations in EGFR have different clinicopathological characteristics and clinical significance. It was noticed that patients with EGFR mutation in exon 19 had higher sensitive rates to TKI drugs and increased survival rates after treatment with TKI drugs in contrast to those with exon 21 mutations [11, 13-18], while some research groups didn't think so [19]. Shigematsu et al from Japan even thought patients with EGFR mutations of exon 21 exhibited an increase in survival if they had not received any form of chemotherapy including TKI drugs when compared to those with mutations of exon 19 [2]. Therefore it's significant and necessary to explore the association of the mutations with clinical characters and supplement data about it from areas as many as possible in order to make the question clear.

In this study, we continually detected the character of EGFR and KRAS mutations in NSCLC patients of mainland China. Additionally, we analyse the differences of clinicopathological characteristics between NSCLC patients who exhibit EGFR mutations in exon 19 and 21 in order to explore the carcinogenesis and clinical significance of these mutations in NSCLCs, with the hope of improving NSCLC treatment with EGFR TKI drugs.

\section{Patients and methods}

Patients and tissue samples. Tumor specimens, along with matched normal lung tissues around tumors were collected from 157 patients with NSCLC who underwent surgical procedures at the affiliated hospitals of the Dalian Medical University from July 2007 to May 2009 and patients examined for study had not previously sought any conventional chemotherapy or radiotherapy before. Of the 157 patients, there were 90 men and 67 women with a mean \pm SD age of $62.4 \pm 9.2$ years (range $38-80$ years). All tumors were diagnosed by two certified pathologists. The tumors included 48 squamous cell carcinomas, 97 adenocarcinomas, 4 adenosquamous carcinoma, 5 large cell carcinomas and 3 sarcomatoid carcinomas. Of the 97 adenocarcinomas, there were 17 mixed adenocarcinomas with bronchioloalveoloar components (AWBC) or bronchioloalveolar adenocarcinomas (BAC). There were 58 patients with a history of smoking, 99 patients without it. Lymph node metastasis was pathologically found in 85 cases, not in others. There were 89 patients with clinical stage I and II, 68 patients with III and IV. Of the tumors, 74 were obtained from the left lung, and 83 from the right. All tissue samples were collected with the approval of The Ethics Committee of the Dalian Medical University and with the informed consent of the patients or families before surgical procedures.

DNA extraction. DNA extraction of every sample, either tumor or the matched normal lung tissue, was performed according to the protocol described previously [20].

\section{Polymerase chain reaction}

EGFR exon 19, 21 were amplified for mutation detection with high resolution melting analysis with a total volume of $10 \mu \mathrm{l}$ reaction mixture with a $15 \mu \mathrm{l}$ mineral oil overlay in each well on a 96 well PCR plate. The reaction mixture contained $1 \times$ PCR buffer (TaKaRa), $1.5 \mathrm{mM} \mathrm{MgCl}_{2}$ (EGFR exon 21 with $1.8 \mathrm{mM} \mathrm{MgCl}_{2}$ ), $200 \mu \mathrm{M}$ dNTPs, $0.25 \mathrm{U}$ Taq (TaKaRa) (EGFR exon 19 with hotstart Taq), 20ng genomic DNA, $0.5 \mathrm{uM}$ forward primer, $0.5 \mathrm{uM}$ reverse primer, and $1 \mathrm{x}$ LCGreen PLUS ${ }^{\circledR}$ (Idaho Technology). Primer 1 was designed to span from codon 731 to codon 761 of EGFR exon 19, containing 106 base pair (bp). The sequences of Primer 1 [21] were 5'-TGGATCCCAGAAGGTGAGAA -3' (forward) and 5'-AGCAGAAACTCACATCGAGGA -3' (reverse). Primer 2 was designed to span codon 858 and 861 of EGFR gene exon 21, containing 92bp. The sequences of Primer 2 were 5'-CGCAGCATGTCAAGATCA -3' (forward) and 5'-CCTCCTTACTTTGCCTCC -3' (reverse). PCR was performed on a Mastercycler (Eppendorf). The samples were denatured at $95^{\circ} \mathrm{C}$ for 10 minutes, and followed by 45 cycles consisting of a denaturation step at $95^{\circ} \mathrm{C}$ for 30 seconds, an annealing step at $53.4^{\circ} \mathrm{C}$ for 10 seconds, and an extension step at $72^{\circ} \mathrm{C}$ for 1 minute with primer 1 and denatured at $95^{\circ} \mathrm{C}$ for 2 minutes, 45 cycles consisting of a denaturation step at $95^{\circ} \mathrm{C}$ for 30 seconds, an annealing step at $61^{\circ} \mathrm{C}$ for 10 seconds, and an extension step at $72^{\circ} \mathrm{C}$ for 30 seconds with primer 2 .

EGFR exon 19 and 21 were amplified for sequencing with a total volume of $40 \mu \mathrm{l}$ reaction mixture in $200 \mu \mathrm{l}$ PCR tubes. The reaction mixture contained $1 \times$ PCR buffer with $1.5 \mathrm{mM}$ MgCl2 (TaKaRa), $200 \mu \mathrm{M}$ dNTPs, 1 U Taq (TaKaRa), 80ng genomic DNA, $1 \mu \mathrm{M}$ forward primer, $1 \mu \mathrm{M}$ reverse primer. EGFR exon 19 and 21 were amplified with primers previously published by Paez et al [9]. The samples were denatured at $95^{\circ} \mathrm{C}$ for 2 minutes, 45 cycles consisting of a denaturation step at $95^{\circ} \mathrm{C}$ for 30 seconds, an annealing step at $60.8{ }^{\circ} \mathrm{C}$ for 10 seconds (EGFR exon 21 with $57.3^{\circ} \mathrm{C}$ ), and an extension step at $72{ }^{\circ} \mathrm{C}$ for 30 seconds.

KRAS exon 2 amplified for HRMA and sequencing have been described previously [20].

\section{High resolution melting analysis}

In a 96-well PCR plate, each sample was analyzed in triplicate. Deionized water was used in a non-template control well (no genomic DNA was added) and DNA without EGFR exon 19, 21 and KRAS exon 2 mutations which proved by sequencing was used as a wild type control sample. The tumor 
tissue and the matched normal lung tissue from the same patients were analyzed in the same PCR plate. When samples were amplified in 96-well plates, melting curve acquisition was performed on the LightScanner ${ }^{\text {Tw }}$ (Idaho Technology). The PCR products and melting curves were analyzed using the LightScanner ${ }^{\text {TI }}$ software (version 2.0) according to the manufacturer's instructions.

\section{DNA sequencing}

The samples with EGFR exon 19 or exon 21 or KRAS exon 2 mutation detected by HRM were identified by sequencing. Forty samples (tumor samples or the matched normal lung tissues) without any mutation of the 3 exons were selected randomly to sequence. PCR products were sequenced with a BigDye Terminator v3.1 Cycle Sequencing Kit, performed on an ABI PRISM 3730XL DNA Analyzer and an ABI PRISM 377XL DNA Sequencer.

Statistics. Associations between the types of EGFR and KRAS mutations detected and clinical pathological and histological features were evaluated with chi-square tests, Fisher's exact tests and nonparametric test using SPSS 13.0 statistical software. Values of $p<0.05$ were considered significant.

\section{Results}

EGFR and KRAS mutation detection by HRM analysis and sequencing in NSCLCs. Of 157 NSCLC cases examined, $57(36.3 \%, 57 / 157)$ cases were EGFR mutations, which included $22(61.4 \%, 35 / 57)$ in exon 19 and $35(38.6 \%, 22 / 57)$ in exon 21 , and $11(7.0 \%, 11 / 157)$ cases with KRAS mutations. The mutation frequency in EGFR was significantly higher than that in KRAS $(P=0.000)$. The mutation frequency of EGFR in exon 21 was higher than that in exon 19, but it was not significant between them $(P=0.057)$. All mutations were solely detected in lung cancer samples, not in any matched normal lung tissue. It was not found double mutations of EGFR in exon 19 and 21 or mutations of both EGFR and KRAS in any sample.

We further sequenced the 68 samples with EGFR or KRAS mutations and 40 samples selected randomly without any mutation of the 3 exons detected by HRM, including 27 tumor samples and 13 matched normal lung tissues. All mutations selected by HRM were proved by sequencing. It was found that there were 6 types of deletion mutation in EGFR exon 19, 4 types of point mutation in EGFR exon 21 and 6 types of point mutation in KRAS exon 2 (Table 1). None of the 40 samples without any mutation by HRM were shown any mutation detected by sequencing.

\section{Correlation of EGFR and KRAS mutations with clinicopathological characteristics}

EGFR mutations were more frequent in females than in males ( $52.2 \%$ vs. $24.4 \%$, respectively; $P=0.000)$, and in nonsmokers than in smokers $(47.5 \%$ vs. $17.2 \%$, respectively; $P=0.000)$. EGFR mutation were significantly associated with pathological types $(P=0.000)$, with the highest mutation ratio being found in adenocarcinomas $(51.5 \%)$, followed by adenosquamous carcinomas (50.0\%) and then squamous cell carcinomas comprising the lowest ratio (8.3\%). It was not significantly associated with ages, tumor sites, types of adenocarcinoma, lymph metastasis or clinical stages (Table 2).

KRAS mutations were more frequently found in males than in females ( $11.1 \%$ vs. $1.5 \%$, respectively; $P=0.025)$. There were no significant relationship of the mutations to ages, tumor sites, tumor stages and histological types $(P>0.05)$ (Table 2$)$.

Differences of clinicopathological characteristics in patients with EGFR mutation in exon 19 and 21 separately.

Table 1. EGFR and KRAS mutations detected by sequencing

\begin{tabular}{|c|c|c|c|}
\hline gene & Nucleotide alteration & Amino acid alteration & Number of samples \\
\hline \multirow[t]{6}{*}{ EGFR exon19 } & 2235_2249del & $\Delta \mathrm{E} 746 \_\mathrm{A} 750$ & 13 \\
\hline & 2236_2250del & DE746_A750 & 3 \\
\hline & 2237_2251del+TGGins & $\Delta$ E746_T751(insAW) & 1 \\
\hline & 2239_2253del & $\Delta \mathrm{L} 747 \_\mathrm{S} 751$ & 1 \\
\hline & 2239_2256del & $\Delta$ L747_T752 & 1 \\
\hline & 2240_2257del & $\Delta$ L747_P753(insS) & 3 \\
\hline \multirow[t]{4}{*}{ EGFR exon 21} & $2573 \mathrm{~T}>\mathrm{G}$ & L858R & 30 \\
\hline & $2582 \mathrm{~T}>\mathrm{A}$ & L861Q & 3 \\
\hline & $2546 \mathrm{~A}>\mathrm{G} ; 2573 \mathrm{~T}>\mathrm{G}$ & Q849R; L858R & 1 \\
\hline & $2497 \mathrm{~T}>\mathrm{G} ; 2573 \mathrm{~T}>\mathrm{G}$ & L833V; L858R & 1 \\
\hline \multirow[t]{6}{*}{ KRAS exon2 } & $215 G>T$ & G12C & 4 \\
\hline & $215 G>A$ & G12S & 1 \\
\hline & $216 \mathrm{G}>\mathrm{T}$ & G12V & 2 \\
\hline & $216 \mathrm{G}>\mathrm{A}$ & G12D & 2 \\
\hline & $219 \mathrm{G}>\mathrm{A}$ & G13D & 1 \\
\hline & $216 \mathrm{G}>\mathrm{A} ; 227 \mathrm{~A}>\mathrm{T} ; 235 \mathrm{C}>\mathrm{T}$ & G12D; K16stop codon; A18A & 1 \\
\hline
\end{tabular}


Table 2. Association of EGFR and KRAS mutations with clinicopathological characteristics in NSCLC patients

\begin{tabular}{|c|c|c|c|c|c|}
\hline Variables & No. of cases & $\begin{array}{c}\text { No. (\%) of all EGFR } \\
\text { mutations }\end{array}$ & $P$ values & $\begin{array}{l}\text { No. }(\%) \text { of KRAS } \\
\text { mutations in exon } 2\end{array}$ & $P$ values \\
\hline \multicolumn{6}{|l|}{ Age } \\
\hline$\leq 60$ & 67 & $24(35.8)$ & 0.913 & $5(7.5)$ & 1.000 \\
\hline$>60$ & 90 & $33(36.7)$ & & $6(6.7)$ & \\
\hline \multicolumn{6}{|l|}{ Gender } \\
\hline Female & 67 & $35(52.2)$ & 0.000 & $1(1.5)$ & 0.025 \\
\hline Male & 90 & $22(24.4)$ & & $10(11.1)$ & \\
\hline Pathology & & & 0.000 & & 0.861 \\
\hline SCC & 48 & $4(8.3)$ & & $4(8.3)$ & \\
\hline ASC & 4 & $2(50.0)$ & & $0(0.0)$ & \\
\hline Adc & 97 & $50(51.5)$ & 0.346 & $7(7.2)$ & 0.101 \\
\hline $\mathrm{AWBC}$ or BAC & 17 & $3(17.6)$ & & $3(17.6)$ & \\
\hline Other Adc & 80 & $47(58.8)$ & & $4(5.0)$ & \\
\hline \multicolumn{6}{|l|}{ Smoking history } \\
\hline Non-smokers & 99 & $47(47.5)$ & 0.000 & $5(5.1)$ & 0.331 \\
\hline Smokers & 58 & $10(17.2)$ & & $6(10.3)$ & \\
\hline \multicolumn{6}{|l|}{ Site of the tumor } \\
\hline Left lung & 74 & $30(40.5)$ & 0.297 & $7(9.5)$ & 0.256 \\
\hline Right lung & 83 & $27(32.5)$ & & $4(4.8)$ & \\
\hline \multicolumn{6}{|l|}{ LN metastasis } \\
\hline No & 72 & $24(33.3)$ & 0.476 & $8(11.1)$ & 0.064 \\
\hline Yes & 85 & $33(38.8)$ & & $3(3.5)$ & \\
\hline \multicolumn{6}{|l|}{ Stage } \\
\hline I \& II & 89 & 37 (41.6) & 0.116 & $6(6.7)$ & 1.000 \\
\hline III \& IV & 68 & $20(29.4)$ & & $5(7.4)$ & \\
\hline
\end{tabular}

SCC: squamous cell carcinomas, Adc: adenocarcinomas, ASC: adenosquamous carcinoma, AWBC: mixed adenocarcinomas with bronchioloalveoloar components, BAC: bronchioloalveolar adenocarcinomas, LN: lymph node.

Patients with exon 19 mutations had significantly higher frequency in adenocarcinomas than squamous cell carcinomas ( $21.6 \%$ vs. $2.1 \%$, respectively; $P=0.001$ ), in non-smokers than in smokers ( $18.2 \%$ vs. $6.9 \%$, respectively; $P=0.049$ ). Additionally, tumors with exon 19 mutations in left lung were more frequent than in right lung $(21.6 \%$ vs. $7.2 \%$, respectively; $P=0.010)$ and in the I \& II stages than in the III \& IV stages ( $19.1 \%$ vs. $7.4 \%$, respectively; $P=0.036$ ), but the mutation had no relationship with ages, genders, adenocarcinoma types and lymph metastasis (Table 3 ).

Patients with exon 21 mutations had significantly higher frequency in females than in males $(32.8 \%$ vs. $14.4 \%$, respectively; $P=0.006)$, in adenosquamous carcinomas and adenocarcinomas than in squmous cell carcinomas $(50.0 \%$ and $29.9 \%$ vs. $6.3 \%$, respectively; $P=0.003)$, in non-smokers than in smokers ( $29.3 \%$ vs. $10.3 \%$, respectively; $P=0.006)$. However, the mutation was no related to ages, adenocarcinoma types, tumor sites, lymph metastasis and clinical stages of the patients $(P>0.05)$ (Table 3).

We compared EGFR mutation frequencies in exon 19 to that in exon 21 in subgroups of clinicopathological characteristics. We found that the mutation frequencies of EGFR mutation in exon 21 were significantly higher than those in exon 19 in the right lung tumors $(25.3 \%$ vs. $7.2 \%, 0.002)$, tumors with lymph node metastasis ( $25.9 \%$ vs. $12.9 \%, 0.033)$ and in the III \& IV stages $(22.1 \%$ vs. $7.4 \%, 0.015)$. The mutation frequencies in exon 21 were higher than those in exon 19 in female and non-smoking patients, but there was no significant difference $(P>0.05)$ (Table 4).

We didn't found there were any significant differences, between the left lung tumors and the right ones, in ages, genders, pathology types, smoking history, lymph node metastasis and tumor stages $(P>0.05)$ (Table 5$)$.

\section{Discussion}

EGFR and KRAS are two integral regulatory genes that operate on the same signal transduction pathway that could lead cells to abnormal proliferation and malignant transformation if active mutations occur to either of them [22]. Recently, it was found that EGFR mutation was a sensitive marker of NSCLC to EGFR TKI drugs, while KRAS mutation was a resistant one $[22,23]$. Considering the incidence of gene mutations including EGFR and KRAS in NSCLC varied regionally and racially, we detected EGFR and KRAS mutations in 157 NSCLC patients from mainland China, and found that the mutation 
Table 3. Association of two type EGFR mutations with clinicopathological characteristics in NSCLC patients

\begin{tabular}{|c|c|c|c|c|c|}
\hline Variables & No. of cases & $\begin{array}{c}\text { No. (\%) of EGFR } \\
\text { mutations in exon } 19\end{array}$ & $P^{l}$ values & $\begin{array}{c}\text { No. }(\%) \text { of EGFR } \\
\text { mutations in exon } 21\end{array}$ & $P^{2}$ values \\
\hline \multicolumn{6}{|l|}{ Age } \\
\hline$\leq 60$ & 67 & $9(13.4)$ & 0.857 & $15(22.4)$ & 0.980 \\
\hline$<60$ & 90 & $13(14.4)$ & & $20(22.2)$ & \\
\hline \multicolumn{6}{|l|}{ Gender } \\
\hline Female & 67 & $13(19.4)$ & 0.093 & $22(32.8)$ & 0.006 \\
\hline Male & 90 & $9(10.0)$ & & $13(14.4)$ & \\
\hline Pathology & & & 0.001 & & 0.003 \\
\hline SCC & 48 & $1(2.1)$ & & $3(6.3)$ & \\
\hline ASC & 4 & $0(0.0)$ & & $2(50.0)$ & \\
\hline Adc & 97 & $21(21.6)$ & 1.000 & $29(29.9)$ & 0.528 \\
\hline AWBC or BAC & 17 & $3(17.6)$ & & $4(23.5)$ & \\
\hline Other Adc & 80 & $18(22.5)$ & & $25(31.3)$ & \\
\hline \multicolumn{6}{|l|}{ Smoking history } \\
\hline Non-smokers & 99 & $18(18.2)$ & 0.049 & $29(29.3)$ & 0.006 \\
\hline Smokers & 58 & $4(6.9)$ & & $6(10.3)$ & \\
\hline \multicolumn{6}{|l|}{ Site of the tumor } \\
\hline Left lung & 74 & $16(21.6)$ & 0.010 & $14(18.9)$ & 0.338 \\
\hline Right lung & 83 & $6(7.2)$ & & $21(25.3)$ & \\
\hline \multicolumn{6}{|l|}{ LN metastasis } \\
\hline No & 72 & $11(15.3)$ & 0.674 & $13(18.1)$ & 0.240 \\
\hline Yes & 85 & $11(12.9)$ & & $22(25.9)$ & \\
\hline \multicolumn{6}{|l|}{ Stage } \\
\hline I \& II & 89 & $17(19.1)$ & 0.036 & $20(22.5)$ & 0.951 \\
\hline III \& IV & 68 & $5(7.4)$ & & $15(22.1)$ & \\
\hline
\end{tabular}

$P^{l}$ values: comparing the tumors with EGFR mutations in exon 19 to those without the mutations; $P^{2}$ values: comparing the tumors with EGFR mutations in exon 21 to those without the mutations.

Table 4. Different clinicopathological characteristics between NSCLC patients with EGFR mutations in exon 19 and 21

\begin{tabular}{|c|c|c|c|c|}
\hline Variables & No. of cases & $\begin{array}{l}\text { No. (\%) of EGFR mutations } \\
\text { in exon } 19\end{array}$ & $\begin{array}{l}\text { No. (\%) of EGFR mutations } \\
\text { in exon } 21\end{array}$ & $P$ values \\
\hline \multicolumn{5}{|l|}{ Age } \\
\hline$\leq 60$ & 67 & $9(13.4)$ & $15(22.4)$ & 0.176 \\
\hline$<60$ & 90 & $13(14.4)$ & $20(22.2)$ & 0.178 \\
\hline \multicolumn{5}{|l|}{ Gender } \\
\hline Female & 67 & $13(19.4)$ & $22(32.8)$ & 0.077 \\
\hline Male & 90 & $9(10.0)$ & $13(14.4)$ & 0.363 \\
\hline \multicolumn{5}{|l|}{ Pathology } \\
\hline SCC & 48 & $1(2.1)$ & $3(6.3)$ & 0.617 \\
\hline Adc & 97 & $21(21.6)$ & $29(29.9)$ & 0.189 \\
\hline \multicolumn{5}{|l|}{ Smoking history } \\
\hline Non-smokers & 99 & $18(18.2)$ & $29(29.3)$ & 0.078 \\
\hline Smokers & 58 & $4(6.9)$ & $6(10.3)$ & 0.508 \\
\hline \multicolumn{5}{|l|}{ Site of the tumor } \\
\hline Left lung & 74 & $16(21.6)$ & $14(18.9)$ & 0.683 \\
\hline Right lung & 83 & $6(7.2)$ & $21(25.3)$ & 0.002 \\
\hline \multicolumn{5}{|l|}{ LN metastasis } \\
\hline No & 72 & $11(15.3)$ & $13(18.1)$ & 0.655 \\
\hline Yes & 85 & $11(12.9)$ & $22(25.9)$ & 0.033 \\
\hline \multicolumn{5}{|l|}{ Stage } \\
\hline I \& II & 89 & $17(19.1)$ & $20(22.5)$ & 0.579 \\
\hline III \& IV & 68 & $5(7.4)$ & $15(22.1)$ & 0.015 \\
\hline
\end{tabular}


frequencies of EGFR and KRAS were both similar to reports from other East Asia areas, such as Taiwan China, Japan and Korea [19,24-28]. Comparing to western countries, the mutation frequency of EGFR was higher, while that of KRAS was lower in the East Asia areas [20, 29, 30]. Moreover, the EGFR mutation was more commonly found in women, while KRAS mutation more in men. As well as mutations of the two genes were exclusive [11]. All these suggested that mutations of EGFR and KRAS play a key role in the carcinogenesis of NSCLC independently according to ethnic and gender. In mainland China, the EGFR mutations were more common than KRAS in NSCLC patients.

Generally speaking, EGFR mutations, more than $90 \%$ of them focused in exon 19 and exon 21, occur more frequently in NSCLC patients of women, non-smokers, pathological subtype of adenocarcinoma and east Asian ethincs [7-9]. We obtained similar results when EGFR mutations in exon 19 and exon 21 were taken as a whole. But when we analyse the association of either mutation in exon 19 or in exon 21 with the clinicalpathological characters separately, we found that the incidence of female patients with mutations in exon 19 was not significantly higher than that of male ones, on the contrary, it did in patients with mutations in exon 21. It indicated that, in mainland China, a higher frequency of EGFR mutations in females was induced by higher incidence of mutations in exon 21, but not in exon 19. At the same time we found that patients with mutations in exon 19 were more frequent in stage I and II, while not in stage III and IV. Moreover, comparing to the frequencies of EGFR mutation in exon 19, those in exon 21 were significantly higher both in tumors with lymph node metastasis and in clinical stage III and IV, while in tumors without lymph node metastasis and in clinical stage I and II, the mutation frequencies were not different significantly between in exon 19 and 21. These indicated that the NSCLCs with mutations in exon 21 have more malignant characteristic than those with mutations in exon 19. It suggested that subtypes of EGFR mutations could have different mechanisms in the carcinogenesis of NSCLC, which would then affect the outcome of patients.

Recently, several groups noticed that NSCLCs with mutation in exon 19 were more sensitive to TKI drugs than those with mutation in exon 21. It would be a result of different biochemical signalling properties acting upon receptors encoded by the two types of mutations. The amino acids coded by the two exons conjointly constitute the tyrosine kinase domain, which is an important functional domain of EGFR. The EGFR tyrosine kinase domain consists of an N-terminal ( $\mathrm{N}$ lobe), and C-terminal (C lobe). ATP binding cleft (P-loop) lies between $\mathrm{N}$ lobe and $\mathrm{C}$ lobe. $\mathrm{N}$ lobe consists of a $\beta$-sheet and the highly conserved $\alpha \mathrm{C}$ helix which participates in regulation the activation of the P-loop. Moreover, the $\mathrm{C}$ lobe consists of an activation loop (A-loop), which could activate downstream protein following its phosphorylation [31, 32]. Deletion mutation of exon 19 is on one side of $a \mathrm{C}$ helix and point mutation of exon 21 exists near A-loop. These two types
Table 5. Association of tumor sites with clinicopathological characteristics in NSCLC patients

\begin{tabular}{|c|c|c|c|c|}
\hline Variables & No. of cases & Left lung & Right lung & $P$ values \\
\hline Age & & & & 0.349 \\
\hline$\leq 60$ & 66 & 28 & 38 & \\
\hline$<60$ & 90 & 45 & 45 & \\
\hline Gender & & & & 0.540 \\
\hline Female & 66 & 29 & 37 & \\
\hline Male & 90 & 44 & 46 & \\
\hline Pathology & & & & 0.115 \\
\hline ASC & 4 & 2 & 2 & \\
\hline SCC & 48 & 28 & 20 & \\
\hline Adc & 97 & 43 & 54 & 0.185 \\
\hline $\mathrm{AWBC}$ or Bac & 17 & 10 & 7 & \\
\hline Other Adc & 80 & 33 & 47 & \\
\hline Smoking history & & & & 0.963 \\
\hline Non-smokers & 98 & 46 & 52 & \\
\hline Smokers & 58 & 27 & 31 & \\
\hline LN metastasis & & & & 0.458 \\
\hline No & 72 & 36 & 36 & \\
\hline Yes & 84 & 37 & 47 & \\
\hline Stage & & & & 0.158 \\
\hline I \& II & 89 & 46 & 43 & \\
\hline III \& IV & 67 & 27 & 40 & \\
\hline
\end{tabular}

of mutations both increase EGFR activation by autophosphorylation, leading cells to malignant transformation. TKI drugs can bind to the ATP-binding pocket and inhibit downstream signal transductions [32]. The mutations in exon 19 and 21 of EGFR can change the pocket configuration to be more firmly combined with TKIs. It was reported that deletion mutation in exon 19 was higher phosphorylated than L858R missense mutation in exon 21 [33]. Therefore different type mutations (point and the deletion) may cause different configurational changes, which may be the biochemical basis of the difference in carcinogenesis and sensitivity to TKIs.

Our results found that the NSCLCs with EGFR mutation in exon 19 presented a less malignant character, as well as having more sensitivity to TKIs than those with mutation in exon 21. Therefore it could be the basis that China patients with mutation in exon 19 had better survival than those with mutation in exon 21, as reported from some groups [13-15, 17].

Interestingly, we found that the NSCLCs with EGFR mutations in exon 19 were significantly more common in the left lung than those in the right. And in the group of NSCLCs found in the right lung, the frequency of mutation in EGFR exon 21 was significantly higher than that in exon 19. KRAS mutation was not related to the tumor sites. We analysed the relationships of the tumor sites of the lung (the left and the right) to other clinicopathological characters, including age, gender, pathological types, smoking history, lymph node metastasis and tumor stages, but did not find significant relationship (Table 4). It was indicated that mutation subtypes 
of EGFR were related to tumor site; however, they were not caused by an error of sample selection. One postulate may be an association with the embryogenesis and post-natal microenvironment. Toyooka et al found that one NSCLC patient has both exon 19 deletion and exon 21 point mutation on two different tumors, respectively [34]. Several other groups reported that both EGFR mutation in exon 19 and exon 21 were found in the same patients, but it was not reported if the tumors were on one side or both sides of lung [17, 19, 35]. Further research is needed to prove if the mutation types of EGFR are associated with tumor sites which may then hopefully open up new ways of exploring the carcinogenesis and TKI drug therapy in NSCLCs.

In short, EGFR mutations are more common than KRAS mutations in NSCLC patients from mainland China. Higher female mutation frequency of EGFR is mainly caused by the high mutation frequency in exon 21, but not in exon 19 in mainland China. Tumor sites and gender could be related to the mutation subtypes of EGFR in NSCLCs. It's the first report that EGFR mutations in exon 19 and exon 21 in NSCLC patients may relate to the tumor sites, though the reason is not clear.

Acknowledgements. This work was supported by Dalian Merricom gene diagnosis technology Co., Ltd. We thank Robert Jesky for critical reading of the manuscript.

\section{References}

[1] SHIGEMATSU H, GAZDAR AF. Somatic mutations of epidermal growth factor receptor signaling pathway in lung cancers. Int J Cancer 2006; 118: 257-262. doi:10.1002/ijc.21496

[2] SHIGEMATSU H, LIN L, TAKAHASHI T, NOMURA M, SUZUKI $M$ et al. Clinical and biological features associated with epidermal growth factor receptor gene mutations in lung cancers. J Natl Cancer Inst 2005; 97: 339-346. doi:10.1093/ jnci/dji055

[3] SORDELLA R, BELL DW, HABER DA, SETTLEMAN J. Gefitinib-sensitizing EGFR mutations in lung cancer activate anti-apoptotic pathways. Science 2004; 305: 1163-1167. doi:10.1126/science.1101637

[4] SCAGLIOTTI GV, SELVAGGI G, NOVELLO S, HIRSCH FR. The biology of epidermal growth factor receptor in lung cancer. Clin Cancer Res 2004; 10: 4227s-4232s. doi:10.1158/ 1078-0432.CCR-040007

[5] YAMAMOTO H, TOYOOKA S, MitSUdOMI T. Impact of EGFR mutation analysis in non-small cell lung cancer. Lung Cancer 2009; 63: 315-321. doi:10.1016/ j.lungcan.2008.06.021

[6] UCHIDA A, HIRANO S, KITAO H, OGINO A, RAI K et al. Activation of downstream epidermal growth factor receptor (EGFR) signaling provides gefitinib-resistance in cells carrying EGFR mutation. Cancer Sci 2007; 98: 357-363. doi:10.1111/ j.1349-7006.2007.00387.x

[7] MOLINA JR, ADJEI AA. The Ras/Raf/MAPK pathway. J Thorac Oncol 2006; 1: 7-9. doi:10.1097/01243894-200601000$\underline{00004}$
[8] LYNCH TJ, BELL DW, SORDELLA R, GURUBHAGAVATULA S, OKIMOTO RA et al. Activating mutations in the epidermal growth factor receptor underlying responsiveness of non-small-cell lung cancer to gefitinib. N Engl J Med 2004; 350: 2129-2139. doi:10.1056/NEJMoa040938

[9] PAEZ JG, JANNE PA, LEE JC, TRACY S, GREULICH H et al. EGFR mutations in lung cancer: correlation with clinical response to gefitinib therapy. Science 2004; 304: 1497-1500. doi:10.1126/science.1099314

[10] Do H, Krypuy M, MITCHELL PL, FOX SB, DOBROVIC A. High resolution melting analysis for rapid and sensitive EGFR and KRAS mutation detection in formalin fixed paraffin embedded biopsies. BMC Cancer 2008; 8: 142. doi:10.1186/ 1471-2407-8-142

[11] TAKANO T, OHE Y, TSUTA K, FUKUI T, SAKAMOTO H et al. Epidermal growth factor receptor mutation detection using high-resolution melting analysis predicts outcomes in patients with advanced non small cell lung cancer treated with gefitinib. Clin Cancer Res 2007; 13: 5385-5390. doi:10.1158/1078-0432. CCR-07-0627

[12] TAM IY, CHUNG LP, SUEN WS, WANG E, WONG MC et al. Distinct epidermal growth factor receptor and KRAS mutation patterns in non-small cell lung cancer patients with different tobacco exposure and clinicopathologic features. Clin Cancer Res 2006; 12: 1647-1653. doi:10.1158/1078-0432.CCR-05$\underline{1981}$

[13] RIELY GJ, PAO W, PHAM D, LI AR, RIZVI N et al. Clinical course of patients with non-small cell lung cancer and epidermal growth factor receptor exon 19 and exon 21 mutations treated with gefitinib or erlotinib. Clin Cancer Res 2006; 12: 839-844. doi:10.1158/1078-0432.CCR-05-1846

[14] JACKMAN DM, YEAP BY, SEQUIST LV, LINDEMAN N, HOLMES AJ et al. Exon 19 deletion mutations of epidermal growth factor receptor are associated with prolonged survival in non-small cell lung cancer patients treated with gefitinib or erlotinib. Clin Cancer Res 2006; 12: 3908-3914. doi:10.1158/1078-0432.CCR-06-0462

[15] MITSUDOMI T, KOSAKA T, ENDOH H, HORIO Y, HIDA $\mathrm{T}$ et al. Mutations of the epidermal growth factor receptor gene predict prolonged survival after gefitinib treatment in patients with non-small-cell lung cancer with postoperative recurrence. J Clin Oncol 2005; 23: 2513-2520. doi:10.1200/ LCO.2005.00.992

[16] VAN ZANDWIJK N, MATHY A, BOERRIGTER L, RUIJTER $\mathrm{H}$, TIELEN I et al. EGFR and KRAS mutations as criteria for treatment with tyrosine kinase inhibitors: retro- and prospective observations in non-small-cell lung cancer. Ann Oncol 2007; 18: 99-103. doi:10.1093/annonc/mdl323

[17] ZHU JQ, ZHONG WZ, ZHANG GC, LI R, ZHANG XC et al. Better survival with EGFR exon 19 than exon 21 mutations in gefitinib-treated non-small cell lung cancer patients is due to differential inhibition of downstream signals. Cancer Lett 2008; 265: 307-317. doi:10.1016/ j.canlet.2008.02.064

[18] JACKMAN DM, MILLER VA, CIOFFREDI LA, YEAP BY, JANNE PA et al. Impact of epidermal growth factor receptor and KRAS mutations on clinical outcomes in previously 
untreated non-small cell lung cancer patients: results of an online tumor registry of clinical trials. Clin Cancer Res 2009; 15: 5267-5273. doi:10.1158/1078-0432.CCR-09-0888

[19] WU SG, CHANG YL, HSU YC, WU JY, YANG CH et al. Good response to gefitinib in lung adenocarcinoma of complex epidermal growth factor receptor (EGFR) mutations with the classical mutation pattern. Oncologist 2008; 13: 1276-1284. doi:10.1634/theoncologist.2008-0093

[20] LI M, LIU L, LIU Z, YUE S, ZHOU L et al. The status of KRAS mutations in patients with non-small cell lung cancers from mainland China. Oncol Rep 2009; 22: 1013-1020.

[21] ZHOU L, PALAIS RA, SMITH GD, ANDERSON D, ROWE LR et al. Enrichment and detection of rare alleles by means of snapback primers and rapid-cycle PCR. Clin Chem 2010; 56: 814-822. doi:10.1373/clinchem.2009.142034

[22] KIM YT, KIM TY, LEE DS, PARK SJ, PARK JY et al. Molecular changes of epidermal growth factor receptor (EGFR) and KRAS and their impact on the clinical outcomes in surgically resected adenocarcinoma of the lung. Lung Cancer 2008; 59: 111-118. doi:10.1016/j.lungcan.2007.08.008

[23] ZHU CQ, DA CUNHA SANTOS G, DING K, SAKURADA A, CUTZ JC et al. Role of KRAS and EGFR as biomarkers of response to erlotinib in National Cancer Institute of Canada Clinical Trials Group Study BR.21. J Clin Oncol 2008; 26: 4268-4275. doi:10.1200/JCO.2007.14.8924

[24] JANG TW, OAK CH, CHANG HK, SUO SJ, JUNG MH. EGFR and KRAS mutations in patients with adenocarcinoma of the lung. Korean J Intern Med 2009; 24: 48-54. doi:10.3904/ kjim.2009.24.1.48

[25] HUANG SF, LIU HP, LI LH, KU YC, FU YN et al. High frequency of epidermal growth factor receptor mutations with complex patterns in non-small cell lung cancers related to gefitinib responsiveness in Taiwan. Clin Cancer Res 2004; 10 : 8195-8203. doi:10.1158/1078-0432.CCR-04-1245

[26] NA II, RHO JK, CHOI YJ, KIM CH, KOH JS et al. Clinical features reflect exon sites of EGFR mutations in patients with resected non-small-cell lung cancer. J Korean Med Sci 2007; 22: 393-399. doi:10.3346/jkms.2007.22.3.393
[27] SASAKI H, ENDO K, KONISHI A, TAKADA M, KAWAHARA $M$ et al. EGFR Mutation status in Japanese lung cancer patients: genotyping analysis using LightCycler. Clin Cancer Res 2005; 11: 2924-2929. doi:10.1158/1078-0432.CCR-04-1904

[28] SUGIO K, URAMOTO H, ONO K, OYAMA T, HANAGIRI $\mathrm{T}$ et al. Mutations within the tyrosine kinase domain of EGFR gene specifically occur in lung adenocarcinoma patients with a low exposure of tobacco smoking. Br J Cancer 2006; 94: 896-903. doi:10.1038/sj.bjc.6603040

[29] ROSELL R, MORAN T, QUERALT C, PORTA R, CARDENAL F et al. Screening for epidermal growth factor receptor mutations in lung cancer. N Engl J Med 2009; 361: 958-967. doi:10.1056/NEJMoa0904554

[30] SASAKI H, ENDO K, TAKADA M, KAWAHARA M, KITAHARA $N$ et al. L858R EGFR mutation status correlated with clinico-pathological features of Japanese lung cancer. Lung Cancer 2006; 54: 103-108. doi:10.1016/j.lungcan.2006.06.003

[31] GAZDAR AF, SHIGEMATSU H, HERZ J, MINNA JD. Mutations and addiction to EGFR: the Achilles ,heal' of lung cancers? Trends Mol Med 2004; 10: 481-486.

[32] KUMAR A, PETRI ET, HALMOS B, BOGGON TJ. Structure and clinical relevance of the epidermal growth factor receptor in human cancer. J Clin Oncol 2008; 26: 1742-1751. doi:10.1200/JCO.2007.12.1178

[33] CAREY KD, GARTON AJ, ROMERO MS, KAHLER J, THOMSON S et al. Kinetic analysis of epidermal growth factor receptor somatic mutant proteins shows increased sensitivity to the epidermal growth factor receptor tyrosine kinase inhibitor, erlotinib. Cancer Res 2006; 66: 8163-8171. doi:10.1158/0008-5472.CAN-06-0453

[34] TOYOOKA S, MATSUO K, SHIGEMATSU H, KOSAKA T, TOKUMO $\mathrm{M}$ et al. The impact of sex and smoking status on the mutational spectrum of epidermal growth factor receptor gene in non small cell lung cancer. Clin Cancer Res 2007; 13: 5763-5768. doi:10.1158/1078-0432.CCR-07-0216

[35] YATABE Y, MITSUDOMI T. Epidermal growth factor receptor mutations in lung cancers. Pathol Int 2007; 57: 233-244. doi:10.1111/j.1440-1827.2007.02098.x 